\title{
RECOMPENSAS: UNA INCONGRUENCIA DE ORDEN FILOSÓFICO SOCIAL Y JURÍDICO, EN UN ESTADO SOCIAL DE DERECHO COMO EL QUE SE PREDICA EN COLOMBIA*
}

\author{
A PHILOSOPHICAL INCONSISTENCY OF \\ SOCIAL ORDER AND LEGAL, IN A SOCIAL \\ STATE OF LAW SUCH AS THE ONE THAT IS \\ PREACHED IN COLOMBIA \\ GRATIFICAÇÕES: UMA INCONGRUÊNCIA \\ DA ORDEM FILOSÓFICA Y JURÍDICA, EM \\ UM ESTADO SOCIAL DE DIREITO COMO O \\ QUE SE PREDICA NA COLÔMBIA
}

Nancy Solano de Jinete ${ }^{a}$ nancy_sol@hotmail.com

Over Humberto Serranob overserrano@gmail.com Recibido: 25 de Febrero 2013 Aceptado: 04 de Abril 2013

\section{RESUMEN}

El presente trabajo de investigación tiene un enfoque a partir de la seguridad democrática vinculada al tema de recompensas y el pago de bonificaciones a los desmovilizados. Referir al mismo en un marco de las recompensas nacionales cuyo fin motiva la entrega o denuncia a connacionales, lo que implica una tensión de ser negativa dentro de un Estado Social de Derecho o un deber del Estado por proteger a la sociedad, del flagelo del narcotráfico, la delincuencia común, delincuencia organizada, por así decirlo.

\footnotetext{
*Articulo resultado del trabajo de investigación: "APORTE A LA LEYDE RECOMPENSAS EN LA DINÁMICA DE SOLUCIÓN AL CONFLICTO ARMADO", realizada en la Facultad de Derecho por los autores conforme a convocatoria interna de la Universidad Colegio Mayor de Cundinamarca.

a. Docente investigadora universitaria; especialista en Gestión Pública y Magíster en Educación Superior con énfasis en Investigación. Tratadista: Derechos de Autor en el ámbito Universitario, La Corte Penal Internacional, Creación, operatividad y sus relaciones con el Derecho Constitucional y el Derecho Penal Colombiano, Pedagogía del Derecho en el siglo XXI, Metodología de la Investigación Socio Jurídica y artículos del orden jurídico, pedagógico y derecho autoral en la Revista: Misión Jurídica", Diario de campo de la U.C.M.C. Investigadora y coinvestigadora de investigaciones jurídicas, en el ámbito de la pedagogía del derecho, constitucional, procesal y de los D.D.H.H.
} 
En otras palabras, se tiene que la aplicación de la recompensa conlleva una incongruencia de orden filosófico social y jurídico, en un Estado Social de Derecho como el que se predica en Colombia, no obstante los principios constitucionales consagrar postulados de una democracia participativa, donde el individuo debe acudir a los tribunales en cumplimiento de las garantías procesales y el respeto a su dignidad humana, y negarse a ser un objeto que tiene un valor de recompensa ante la administración de justicia, en que la procura de dichos incentivos lleva a errores que quebrantan el debido proceso.

Lo dicho permite trazar un objetivo general en determinar hasta qué punto las recompensas son incongruentes con el Estado Social de Derecho, en particular con el colombiano, desde una perspectiva filosófica, jurídica y social; y cuáles son los alcances de ello en cuanto al estímulo económico, garantía política y/o de seguridad por parte del Estado.

Finalmente decir que su estudio comprende una visión desde lo constitucional como legal en un contexto de jurisprudencia y doctrina de orden nacional e internacional.

\title{
PALABRAS CLAVE
}

Seguridad democrática, recompensas, bonificaciones, democracia participativa, derechos humanos, ley penal, Estado Social de derecho.

\begin{abstract}
The present work of research has a focus from the democratic security linked to the issue of rewards and payment of allowances to demobilized persons. Refer to it in a framework of national rewards whose purpose motivates delivery complaint or to nationals, which implies a tension of being negative within a Social State of right or a duty of the State to protect society, the scourge of drug trafficking, common crime, organized crime, for so to speak. In other words, is that the application of the reward involves one inconsistency of social and legal, philosophical in a Social State of law as which preaches is in Colombia, despite the constitutional principles consecrated postulates of a participatory democracy, where the individual must go to court in compliance with the procedural guarantees and respect for their human dignity, and refuse be an object that has a value of reward to the administration of Justice, in the pursuit of such incentives lead to mistakes that violate due process. This allows to draw an objective general in determining to what extent the rewards are incongruous with the Social State of law, in particular with the Colombian, from a perspective of philosophical, legal, and social; and what are the scopes of this in terms of the economic stimulus, political guarantee or security by the Estado. Para compliance with the foregoing has specific objectives in the following order: - establish the legal, doctrinal and jurisprudential framework in which the Social rule of law moves to implement the policy of rewards.-unify in the same context the national and international jurisprudential perspective concerning the law of rewards.-determine until point figure of the reward is negative applicability in a social State of law, in particular in
\end{abstract}

y D.I.H. ha realizado ponencias interinstitucionales en los temas señalados, líder del grupo reconocido por Colciencias: Análisis Jurídico.

b. Abogado, doctorando Universidad Externado de Colombia, Magíster Derecho Penal y Criminología U Libre, Magíster Estudios Políticos U Javeriana, docente investigador universitario con varios trabajos de investigación finalizados en materia de derecho penal y derechos humanos, ambiental, publicaciones en las mismas materias, vinculado a las universidades Colegio Mayor de Cundinamarca, La Gran Colombia, Libre. Asesoría y Consultoría en Derecho Penal y Derechos Humanos, ambiental. 
the Colombian. Finally say that their study includes insight from how legal constitutional in a context of national and international doctrine and jurisprudence.

\section{KEY WORDS}

Democratic security, rewards, bonuses, participative, human rights, criminal law democracy, Social State of law.

\section{RESUMO}

O presente trabalho de pesquisa tem o enfoque a partir da segurança democrática vinculada ao tema de gratificações e o pago de bonificações aos desmobilizados. Referir ao mesmo em um marco das gratificações nacionais cujo fim motiva a entrega o denuncia a conacionais, o que implica uma tensão de ser negativa dentro de um Estado Social de Direito ou um dever do Estado por proteger à sociedade do flagelo do narcotráfico, a delinquência comum, delinquência organizada, por assim dizer.

Em outras palavras, a aplicação da gratificação implica ima incongruência da ordem filosófica social e jurídica, em um Estado Social de Direito como o que se predica na Colômbia, não obstante os princípios constitucionais consagrar postulados de uma Democracia participativa, onde o individuo deve acudir aos tribunais em cumprimento de garantias processais e o respeito a sua dignidade humana e negar ser um objeto que tem um valor de gratificação ante a administração de justiça em que a procura de ditos incentivos levam erros que quebrantam o devido processo.

O dito permite traçar um objetivo geral em determinar até qual ponto as gratificações são incongruentes com o Estado Social de Direito, em particular com o colombiano, desde uma perspectiva filosófica, jurídica e social, e quais são alcances disso quanto ao estímulo econômico, garantia política e/ou de segurança por parte do Estado.

Para o cumprimento do anterior tem objetivos especificos da seguinte ordem:

- Estabelecer um marco jurídico, doutrinal e jurisprudencial no qual se move o Estado Social de Direito para implementar a política de gratificações.

- Unificar no mesmo contexto a perspectiva jurisprudencial nacional e internacional relativa à lei de gratificações.

- Determinar até qual ponto a figura da gratificação é de negativa aplicabilidade em um estado social de direito, particularmente no colombiano.

Finalmente, dizer que seu estudo compreende uma visão desde o constitucional como legal em um contexto de jurisprudência e doutrina da ordem nacional e internacional.

\section{PALAVRAS-CHAVE}

Segurança democrática, gratificações, bonificações, democracia participativa, direitos humanos, lei penal, Estado Social de Direito. 


\section{INTRODUCCIÓN}

Hablar de la ley de recompensas en el caso colombiano se ha constituido en una percepción en la cual quienes se someten a sus cánones ni tienen por objetivo contribuir a la solución del conflicto armado, sino un espacio de favorabilidad personal e intereses particulares, dándose una tensión entre la supervivencia como resultado de la fijación de reglas de conducta social, y los esfuerzos para proteger a sus integrantes de los infractores del orden social.

En este contexto la seguridad (utilización legítima de la fuerza) y la justicia (dar a cada uno lo suyo) son un imperativo vital para las libertades individuales, que se han visto empañadas por factores que han distorsionado su real alcance.

Se percibe por el conglomerado social colombiano que el Estado está ampliamente distanciado de la sociedad, donde la expresión de Estado Social de Derecho entra en un marco de duda: se siguen cancelado sumas de dinero por nacionales en un vaivén de intereses mucho más profundos que el deseo de armonía social reflejado en actos de equidad y fraternidad social; por tanto, queda en el contexto actual político, social y económico del país, siguiendo la cantidad de estudios realizados, que los estratos menos favorecidos y los comprometidos en el conflicto armado, son ajenos al ideal de conciencia ciudadana, sino que por el contrario, se trata de programas que pretenden resolver el conflicto en fórmulas de paz, y son captados y asumidos como espacios de beneficio personal, desfigurando el papel del Estado dentro de un Estado Social de Derecho.

Aun el predicar que la sociedad ha depositado su confianza en las autoridades para que mantengan y promuevan los cambios, y aseguren el desarrollo de todos, por medio de instituciones que se organizan para: "La protección, garantía, defensa y respeto de los derechos humanos y la dignidad humana inherente a la persona", ello no debe ser óbice para decir que el Estado debe proveer y mantener las condiciones necesarias para que las personas puedan gozar realmente de todos los derechos. En tal orden se tiene que el bienestar social supone que el Estado realiza todas las acciones para que de manera paulatina sean superadas las condiciones materiales de desigualdad, pobreza e inequidad. Lo que no es concebible con una ley de recompensas donde pocos son beneficiados en su ejercicio práctico.

En otros términos la presente investigación se justifica o tiene su razón de ser en el análisis de la Ley de Recompensas: Ley 418 de 1997, por la cual se consagran unos instrumentos para la búsqueda de la convivencia y la eficacia de la justicia. Con posterioridad se continuará el estudio de los decretos reglamentarios, las directivas permanentes, en especial la de seguridad democrática que es conexa con la recompensa y la directiva permanente que consagra el pago de bonificaciones a los desmovilizados. Así mismo se realizará un análisis de las normas constitucionales y la jurisprudencia, relacionadas con el Estado Social de Derecho, en el cual se enmarca el modelo de Estado en Colombia. También se pretende hacer un análisis del referente internacional, al tratarse de las recompensas, y la experiencia obtenida en los Estados en donde esta figura existe.

De igual manera esta investigación apunta a determinar hasta qué punto la figura de la recompensa es de negativa aplicabilidad en un Estado Social de Derecho, en particular el colombiano, teniendo en cuenta las perspectivas filosóficas, jurídicas y sociales. 
Otra perspectiva que hace necesario indagar respecto al tema de recompensa, es que dicha figura antes que fortalecer el Estado Social de Derecho, propicia al delincuente beneficios económicos por concepto de delaciones.

Finalmente se encuentra que el objetivo principal de las recompensas fue desbordado en el sentido de que los ciudadanos, para obtener el beneficio económico, están dispuestos a trasgredir el ordenamiento legal, y en última instancia ese no era el espíritu de la norma.

\section{PLANTEAMIENTO DEL PROBLEMA}

El aporte de la ley de recompensas en la dinámica de solución al conflicto armado, se percibe en un primer momento contradictorio en el orden de su aplicabilidad para los observadores, pues incorpora situaciones que desvían el espíritu de la norma.

La aplicación de la recompensa implica establecer una incongruencia de orden filosófico, social y jurídico, en un Estado Social de Derecho como el que se predica en Colombia, donde los principios constitucionales consagran los postulados de una democracia participativa donde el individuo debe acudir a los tribunales, en cumplimiento de las garantías procesales y el respeto a su dignidad humana, y no constituirse en un objeto que tiene un valor de recompensa ante la administración de justicia, en que la procura de dichos incentivos llevan a errores que quebrantan el debido proceso.

Por tanto, se hace necesario establecer si el sistema de recompensas aplicado hasta el momento ha contribuido a mejorar el sistema de la administración de justicia, o, por el contrario, ha llevado a menguar las garantías constitucionales y el principio de la dignidad humana. Es decir, llevarnos tal situación a preguntarnos si real y efectivamente existe un aporte de la ley de recompensas en la dinámica de solución al conflicto armado.

\section{OBJETIVO DEL PROYECTO}

\section{OBJETIVO GENERAL}

Determinar hasta qué punto las recompensas son incongruentes con el Estado Social de Derecho, en particular con el colombiano, desde una perspectiva filosófica, jurídica y social; y cuáles son los alcances de ello en cuanto al estímulo económico, garantía política y/o de seguridad por parte del Estado.

\section{OBJETIVOS ESPECÍFICOS}

- Establecer el marco jurídico, doctrinal y jurisprudencial en que se mueve el Estado Social de Derecho para implementar la política de recompensas.

- Unificar en un mismo contexto la perspectiva jurisprudencial nacional e internacional, relativa a la ley de recompensas.

- Determinar hasta qué punto la figura de la recompensa es de negativa aplicabilidad en un estado social de derecho, en particular en el colombiano. 


\section{METODOLOGÍA}

La presente investigación se enmarca dentro de la línea de investigación: "Derecho Penal y Estándares Internacionales", teniendo en cuenta la connotación en el ámbito internacional que ha tenido la aplicación de las recompensas en el conflicto armado en Colombia.

Así las cosas, la recompensa está pasando de ser una política estatal a una práctica social, en virtud de lo cual su prospectiva se presenta enraizada como una costumbre jurídica, de la cual es imprescindible el análisis del contexto político, legal, jurisprudencial y doctrinario, especialmente en lo que se refiere a los procedimientos que la rigen. En el sentido que se ha desdibujado su alcance, y concluir desde un enfoque penal y de derecho internacional comparado, frente al conflicto armado.

De tal manera que la metodología a emplear tendrá como fundamento el diseño descriptivo, que permita registrar a los investigadores, a través de las consultas bibliográficas, a fin de concretar los aspectos centrales de la investigación.

A través de la recolección de información se pretende establecer qué dinámica se maneja en torno al tema de la recompensa, permitiendo efectuar un análisis cuantitativo-cualitativo del manejo que se le está dando, tanto en lo que se refiere a la política estatal como a nivel de los estrados judiciales.

Los resultados de la investigación, previos ajustes y probaciones, serán presentados a través de un instrumento didáctico, que facilite a quienes lo requieran, una información clara y objetiva sobre el tema.

Los investigadores se proponen, además de efectuar una recopilación bibliográfica de doctrina, legislación y jurisprudencia atinente al régimen de recompensas, tanto en el sistema colombiano como en otros países, a fin de recopilar por lo menos una muestra representativa de los casos y procedimientos que se llevan en la actualidad sobre el tema.

\section{RESULTADOS:}

La publicación y socialización, en las instancias competentes, pretende sensibilizar al desmovilizado, comprendiendo el alcance de la norma en el sentido de entender la reincorporación a la vida civil con los beneficios no solo económicos, sino también sociales y jurídicos. En el ámbito académico se adicionará al contenido temático en el área de penal, a fin de que los estudiantes conozcan el alcance de la figura y el espíritu del legislador al consagrar las recompensas, aclarando que no existe ninguna incongruencia con los postulados del Estado Social de Derecho.

\section{MARCO TEÓRICO}

Dentro del marco legislativo referido al tema de recompensas DECRETO 128 del 22 de enero de 2003 considera la Ley 418 de 1997, prorrogada y modificada por la Ley 548 de 1999 y la Ley 782 de 2002, donde se ajustó unos instrumentos en procura de asegurar la vigencia del Estado Social y Democrático de Derecho y garantizar la plenitud de los derechos y libertades 
fundamentales registradas en la Constitución Política y en los Tratados Internacionales aprobados por Colombia de tal forma:

Que la norma anteriormente citada dispone que: "las personas desmovilizadas bajo el marco de acuerdos con las organizaciones armadas al margen de la ley o en forma individual podrán beneficiarse, en la medida que lo permita su situación jurídica, de los programas de reincorporación socioeconómica que para el efecto establezca el Gobierno Nacional;

Que el Gobierno Nacional puede facilitar a los desmovilizados mecanismos que les permitan incorporarse a un proyecto de vida de manera segura y digna;

Que dadas las circunstancias anteriores, es preciso fijar condiciones, que de manera precisa y clara, permitan establecer competencias, asignar funciones y desarrollar los procedimientos para acceder a los beneficios socioeconómicos, una vez iniciado el proceso de reincorporación a la vida civil como consecuencia".

Se acompaña el texto del capítulo II atinente al artículo $3^{\circ}$ proceso de desmovilización, artículo $4^{\circ}$ recepción, artículo $5^{\circ}$ Garantía de los derechos humanos; a lo que se suma el capítulo III que expresa los beneficios preliminares, encontrando el artículo $6^{\circ}$ que reza respecto a los documentos: "El Ministerio del Interior realizará los trámites para entregar al desmovilizado la libreta militar, la cédula de ciudadanía y el certificado de antecedentes judiciales, para lo cual las entidades pertinentes dispondrán lo necesario para asumir los costos que la expedición de tales documentos demande". Así tiene beneficio para salud tanto el desmovilizado y su grupo familiar, Además beneficios por colaboración, por entrega de armas; además en su capítulo IV refiere al proceso de reincorporación a la vida civil y sus beneficios. Se llama la atención en cuanto al capítulo $\mathrm{V}$ que trata la protección y atención de los menores de edad desvinculados y se finaliza con el artículo 31: "Modificado por el Decreto 395 de 2007, artículo 4․ Difusión. Los programas de difusión para incentivar la desmovilización de miembros de los grupos armados organizados al margen de la ley, así como la prevención del reclutamiento en estos grupos, estarán a cargo del Ministerio de Defensa Nacional”.

Si es cierto, las disposiciones al respecto se han incrementado, señalamos las más recientes y aquellas que complementan y mejoran el sistema tales como: Ley 1106 de 2006 1/ publicado Diario Oficial 46.490 (diciembre 22) por medio de la cual se prorroga la vigencia de la Ley 418 de 1997 prorrogada y modificada por las Leyes 548 de 1999 y 782 de 2002 y se modifican algunas de sus disposiciones. Por tanto decreta: $1^{\circ}$ De la prórroga de la ley. Prorróguese por el término de cuatro (4) años, la vigencia de los artículos: $1^{\circ}$ al 14 , del 20 al 28, además 30, 31, 34, 35, 37, los comprendidos entre el 42 y 45, se suman 47, 49, 54, 55, 58, 59, 61,al 64, 66, 68, 69, 72, 74 al 80, 83, 91 92, los 98, 102, 103, los comprendidos entre 106 y 110, 112, 113, 114, 115, 117, 118, 119, 121, entre 123, y 130 de la Ley 418 del 26 de diciembre de 1997, y modificada por las Leyes 548 de 1999 y 782 de 2002. Prorroga los artículos: $2^{\circ}$, al 14, y 15, 16, 17, del19 al 46 de la Ley 782 de 2002.

Valga resaltar su artículo $4^{\mathbf{0}}$ Del Programa de Protección de Testigos de la Fiscalía General de la Nación. El artículo 67 de la Ley 418 de 1997, prorrogada y modificada por las Leyes 548 de 1999 y 782 de 2002, quedará así: Créase con cargo al Estado y bajo la dirección y coordinación de la Fiscalía General de la Nación, el "Programa de Protección a Testigos, Víctimas, Intervinientes en el Proceso y Funcionarios de la Fiscalía", mediante el cual se les otorgará protección integral y asistencia social, lo mismo que a sus familiares hasta el cuarto grado de consanguinidad, segundo de afinidad, primero civil y al cónyuge, compañera o compañero permanente, cuando 
se encuentren en riesgo de sufrir agresión o que sus vidas corran peligro por causa o con ocasión de la intervención en un proceso penal. En los casos en que la vida del testigo o denunciante se encuentre en peligro, la Fiscalía protegerá la identidad de los mismos.

Para efectos de protección por parte del programa, se entenderá por testigo la persona que ha tenido conocimiento de la comisión de un delito, o cualquier otra circunstancia que resulte relevante para demostrar la responsabilidad penal, que en concepto del funcionario judicial competente está en disposición de expresarlo durante la actuación procesal, y de ello se derive un riesgo para su vida o integridad personal. Así mismo, estarán a cargo del programa los testigos de aquellos casos de violación a los derechos humanos e infracción al Derecho Internacional Humanitario, independientemente de que no se haya iniciado el correspondiente proceso penal. Ley 1106 de 2006 5/, señala en su artículo $5^{\circ}$ De las alertas tempranas. El artículo 105 de la Ley 418 de 1997, prorrogada y modificada por las Leyes 548 de 1999 y 782 de 2002, quedará así: Corresponde al Presidente de la República conservar en todo el territorio nacional el orden público y restablecerlo donde fuere turbado. Los Gobernadores y Alcaldes deberán atender de manera urgente las recomendaciones y alertas tempranas emanadas del Gobierno Nacional, especialmente del Ministerio del Interior y de Justicia, tendientes a prevenir, atender y conjurar las situaciones de riesgo que alteren el orden público, y las posibles violaciones a los derechos humanos o el Derecho Internacional Humanitario.

Interesa ver el DECRETO 395 DE 2007 emitido el 14 de febrero que tiene por propósito reglamentar la Ley 418 de 1997 prorrogada y modificada por las Leyes 548 de 1999, 782 de 2002 y 1106 de 2006, y se modifica parcialmente el Decreto 128 de 2003.

Ello en consideración de que la Ley 418 de 1997, prorrogada y modificada por las Leyes 548 de 1999, 782 de 2002 y1106 de 2006, "consagró unos instrumentos para asegurar la vigencia del Estado Social y Democrático y de Derecho y garantizar la plenitud de los derechos y libertades fundamentales reconocidos en la Constitución Política y en los Tratados Internacionales aprobados por Colombia".

La norma citada permite que las personas desmovilizadas bajo el marco de acuerdos con las organizaciones armadas al margen de la ley o en forma individual pueden beneficiarse, en la medida que lo permita su situación jurídica, la ley, o los tratados internacionales suscritos y ratificados por Colombia, de los programas de reincorporación socioeconómica que para el efecto establece el Gobierno Nacional; así puede facilitar a los desmovilizados mecanismos que les permitan incorporarse a un proyecto de vida de manera segura y digna.

Hace referencia al Decreto 128 de 2003 que en su artículo 21 fija condiciones para la entrega de beneficios a las personas que se desmovilicen de manera individual y que adelanten su proceso de reincorporación a la vida civil: Los beneficios socioeconómicos indicados sólo pueden concederse por una sola vez a cada persona, siempre y cuando se cumplan los requisitos y obligaciones que el decreto y los Ministerios del Interior y el de Defensa Nacional determinen, y se perderán cuando culmine el proceso de reincorporación a la vida civil, cuando lo abandone el reincorporado o en los casos que señale el reglamento que expide cada Ministerio.

Además en su artículo 27 determina que la vinculación del reincorporado individual al Programa no podrá exceder de dos (2) años, contados a partir de la fecha en que el Comité Operativo para la Dejación de las Armas, CODA, expida la certificación; igualmente en el 
marco de las negociaciones de paz con los grupos armados ilegales, el Gobierno Nacional definió beneficios de reincorporación para la población desmovilizada colectivamente.

Ahora bien, el Decreto 3360 de 2003 establece que: "la lista de desmovilizados suscrita por los voceros o miembros representantes del grupo armado organizado al margen de la ley que se desmoviliza de forma colectiva, debidamente recibida y aceptada por el Alto Comisionado para la Paz, habilita al desmovilizado para acceder al proceso de reincorporación y sustituye, para todos los efectos, la certificación expedida por el Comité Operativo para la Dejación de las Armas, CODA".

El Decreto 3041 de 2006 establece que las funciones señaladas correspondientes al "Programa para la Reincorporación a la Vida Civil de Personas y Grupos Alzados en Armas", serán realizadas por el Departamento Administrativo de la Presidencia de la República; mientras el Decreto 3043 de 2006 refiere a la creación del Departamento administrativo de la Presidencia de la República la Alta Consejería para la Reintegración Social y Económica de Personas y Grupos Alzados en Armas, que establece dentro de sus funciones: "Diseñar, ejecutar y evaluar la política de Estado dirigida a la reintegración social y económica de las personas o grupos armados al margen de la ley, que se desmovilicen voluntariamente de manera individual o colectiva, en coordinación con el Ministerio de Defensa Nacional, el Ministerio del Interior y de Justicia y la Oficina del Alto Comisionado para la Paz".

A su vez la normatividad define por: "Reintegración la totalidad de los procesos asociados con la reinserción, reincorporación y estabilización social y económica de menores desvinculados y de adultos desmovilizados voluntariamente de manera individual o colectiva. Estos procesos contemplan de manera particular la vinculación y aceptación de estas personas en la comunidad que los recibe, además de la participación activa de la sociedad en general en su proceso de inclusión a la vida civil y legal del país;

Que en virtud de las actividades necesarias para configurar un modelo de atención que responda a las necesidades de toda la población beneficiaria, resulta indispensable adoptar medidas que permitan dar continuidad a los procesos que adelanta cada beneficiario, y que a su vez garanticen la plena reintegración social y económica de las personas que se desmovilicen individual y colectivamente".

Acorde a lo normado en lo concerniente a la recepción, valga decir, la desmovilización individual, a partir del hecho que la persona se presenta ante las autoridades pertinentes, “ el Ministerio de Defensa Nacional presta la ayuda que requiera el desmovilizado y su grupo familiar, cubriendo sus necesidades básicas de alojamiento, alimentación, vestuario, transporte, atención en salud, recreación" En otras palabras, durante el proceso de desmovilización, el "Ministerio de Defensa Nacional proveerá los medios necesarios para el alojamiento de los desmovilizados o gestionará la consecución de instalaciones adecuadas, según determine, de manera que se procure su integridad personal".

Se añade al respecto: "Una vez recibido el desmovilizado por parte del Ministerio de Defensa Nacional, deberá dar aviso de tal circunstancia al Ministerio del Interior en el término de tres (3) días hábiles, y procederá a entregárselo en un término no mayor a quince (15) días calendario adicionales. La entrega física del desmovilizado se hará mediando un acta en la cual constarán los datos iniciales de su individualización, su huella dactilar y las circunstancias de su desmovilización del grupo armado al que pertenecía”. 
Con miras de adelantar la investigación correspondiente y definir la situación jurídica de las personas beneficiarias, el Ministerio del Interior coordina con la Fiscalía General de la Nación y el Consejo Superior de la Judicatura la designación de fiscales y jueces de menores. Además la Defensoría del Pueblo designa abogados de oficio con dedicación exclusiva para ejercer la defensa del desmovilizado.

Dentro de las condiciones, los beneficios socioeconómicos están supeditados al cumplimiento de los requisitos y obligaciones que la ley y la Alta Consejería para la Reintegración Social y Económica de Personas y Grupos Alzados en Armas, y el Ministerio de Defensa Nacional, determinen. Para lo cual se es claro, "No gozarán de ninguno de los beneficios señalados quienes estén siendo procesados o hayan sido condenados por delitos que de acuerdo con la Constitución Política, o la ley o los tratados internacionales suscritos y ratificados por Colombia no puedan recibir esta clase de beneficios".

En cuanto a los programas de difusión para incentivar la desmovilización de miembros de los grupos armados organizados al margen de la ley, así como la prevención del reclutamiento en estos grupos, estarán a cargo del Ministerio de Defensa Nacional.

Los beneficios se pierden en los siguientes eventos:

1. Cuando se considere que se ha cumplido con el proceso de reintegración social y económica, de acuerdo con los criterios previamente establecidos por la Alta Consejería para la Reintegración Social y Económica de Personas y Grupos Alzados en Armas.

2. Cuando el beneficiario incumpla los compromisos adquiridos durante su desmovilización voluntaria y aquellos pactados con la Alta Consejería.

La pérdida de beneficios se establecerá mediante acto administrativo motivado, expedido por la Alta Consejería para la Reintegración Social y Económica de Personas y Grupos Alzados en Armas, frente al cual podrán interponerse los recursos de ley. Así para todos los efectos legales se entiende como reintegrados a todas aquellas personas que se encuentren adelantando procesos de reincorporación a la vida civil.

\section{MARCO CONCEPTUAL}

Recompensa: Estímulo económico que se da en contraprestación suministrada, que lleve a la realización de una actividad militar, que contribuya a la captura de personas perseguidas por la ley.

Según la directiva permanente No. 29 de 2005 se definen las recompensas en los siguientes términos: "Es la retribución en dinero o en especie, que se entrega a una persona natural, por el suministro de datos de interés para las actividades de inteligencia, contrainteligencia e investigación criminal, respecto de actividades delictivas que afecten la seguridad y estabilidad en cualquier región del pais. Sobre conocimiento de actividades delictivas, ubicación de elementos, materiales armamento y equipos de organizaciones y/o sujetos al margen de la ley en un lugar determinado que sirvan de fundamento para la continuación de labores de inteligencia y el posterior planeamiento de operaciones".

En un marco general hace referencia en su cuerpo normativo el Decreto 128 del 22 de enero de 2003; tenemos las generalidades expresada así: 
"Artículo $1^{\circ}$. Politica de reincorporación a la vida civil. La política conducente a desarrollar el programa de reincorporación a la sociedad y los beneficios socioeconómicos reconocidos será fijada por el Ministerio del Interior en coordinación con el Ministerio de Defensa Nacional.

Artículo $2^{\circ}$. Definiciones. Para efectos de la aplicación del presente decreto se adoptan las siguientes definiciones:

Desmovilizado. Aquel que por decisión individual abandone voluntariamente sus actividades como miembro de organizaciones armadas al margen de la ley, esto es, grupos guerrilleros y grupos de autodefensa, y se entregue a las autoridades de la república.

Reincorporado. El desmovilizado certificado por el Comité Operativo para la Dejación de las Armas, CODA, que se encuentre en el proceso de reincorporación a la vida civil.

Grupo familiar. Para aquellos beneficios, diferentes a salud, que involucren la familia, se entiende como grupo familiar del desmovilizado (a), el (la) cónyuge o el (la) compañero (a) permanente, los hijos y, a falta de cualquiera de los anteriores, los padres.

Cuando se trate de compañeros permanentes su unión debe ser superior a los dos años en los términos de la Ley 54 de 1990.

Beneficios. La ayuda humanitaria y los incentivos económicos, jurídicos y sociales que se otorgan a desmovilizados y reincorporados para su regreso a la vida civil.

CODA. Comité Operativo para la Dejación de las Armas.

Certificación del CODA. Es el documento que expide el Comité Operativo para la Dejación de las Armas, CODA, dando cuenta de la pertenencia del desmovilizado a una organización armada al margen de la ley y de su voluntad de abandonarla. Esta certificación permite el ingreso del desmovilizado al proceso de reincorporación y el otorgamiento a su favor, de los beneficios jurídicos y socioeconómicos de que hablan la ley y este Decreto.

\section{REFERENTE INTERNACIONAL}

El referente de las recompensas en el curso de la historia del mundo, y en especial en Colombia, y el análisis conceptual se matiza con lo dicho por el senador mexicano Antonio Santiesteban Ruiz, al proyecto de decreto por el que: "se crea la Ley Federal de Recompensas en Materia Penal y se adiciona el Articulo 49 de la Ley Federal para la administración de Bienes Asegurados, Decomisados y Abandonados", como se establece en trabajos preliminares sobre el tema, donde se capta:

"Ser significativo en la ampliación de las libertades de las personas y la mayor seguridad para las familias y las comunidades. Llevando a decir, ser el combate a la delincuencia una prioridad nacional y tarea de todos.

Se percibe ser México y gran parte de países del orbe amenazados en su seguridad pública debido al alarmante crecimiento de los índices delictivos, llevando a instituciones del Estado a rediseñar sus estrategias y a establecer mecanismos para su efectivo combate. 
Referir hoy a la seguridad, al fenómeno delictual, a las estadísticas de la delincuencia, a la percepción de seguridad o inseguridad, medida esta última en encuestas de opinión, implica un campo particularmente sensible que debe ser tratado con responsabilidad, seriedad, objetividad y rigurosidad. De no ser así, el tratamiento de este fenómeno social se visualiza contaminado, bajo confusión y transformación en un debate estéril, que no ayuda ni aporta elementos que apunten en la dirección que la gran mayoría de mexicanos exige.

Pretermitiendo el análisis estadístico del aumento de la criminalidad en México, se destaca el hecho: Del cambio de calidad y extensión de la criminalidad que se ha experimentado en tal región en el último decenio. Un cambio de condición que tiene que ver con el crecimiento exponencial de los pobres y resultado de la asociación de organizaciones del crimen con determinadas autoridades. El incremento de la pobreza en el país resulta ser un elemento detonante del incremento delincuencial. Sin embargo, se señala, lo fundamental del nuevo fenómeno no encuentra una explicación cabal en la ecuación determinista: a mayor pobreza mayor delincuencia.

Llama la atención no perder de vista que lo que verdaderamente potencializa el problema de la inseguridad, es la apabullante impunidad del delito y sus autores.

El incremento de la cantidad y calidad del delito que se comete, la impunidad con la que se actúa, el despliegue técnico que se observa en determinados secuestros, asesinatos o robos, observa e indica un crimen que rebasó la esfera del individuo o del grupo, desesperados por sobrevivir, para entrar en el terreno de organizaciones criminales claramente profesionalizadas en su actividad y tecnificadas en sus instrumentos. Situación que se ve ocurrir prácticamente en todo el mundo. Reitera, como novedad mexicana la articulación de los grupos organizados para delinquir, con algunas esferas del aparato estatal, configurando una suerte de prerrogativas desde donde se organizan, promueven y protegen dichas actividades.

En la era de la globalización, y rebasando las fronteras, los grupos de criminales han aprovechado las oportunidades que brindan los adelantos tecnológicos para cometer delitos transnacionales como el narcotráfico, el tráfico de personas y el lavado de dinero. Hay que destacar que a consecuencia de las ganancias ilícitas las organizaciones transnacionales delictivas son capaces de atentar contra las sociedades, su forma de gobierno y la seguridad de sus ciudadanos. Ante ello, las naciones han comprendido sobre la necesidad de establecer un marco legal internacional que haga más efectiva la lucha contra estas bandas criminales.

Ya desde la conferencia mundial de Nápoles de 1994, se estableció la necesidad de elaborar una Convención Internacional contra la Delincuencia Organizada Transnacional. Como resultado, en menos de 3 años de negociaciones se llegó a la adopción de un marco legal que haga más efectiva la colaboración multinacional para combatir la delincuencia organizada transnacional. Dicho consenso internacional se mostró claramente en la Conferencia Internacional de Firma del instrumento que fue suscrito por 124 países en Palermo, Italia, en diciembre de 2000.

Es necesario subrayar que lo anterior fue posible como parte de un proceso de evolución de las legislaciones nacionales e internacionales de lucha contra la delincuencia organizada. En el aspecto internacional, pueden destacarse como momentos claves en este proceso: primero, la elaboración de la Convención de las Naciones Unidas contra el tráfico ilícito de Estupefacientes y Sustancias Psicotrópicas de Viena de 1988, sus comentarios y regulación básica a través de leyes modelos; segundo, la elaboración de normas regionales como la de la Organización de 
Estados Americanos (OEA), mediante los trabajos de la Comisión Interamericana para el control del Abuso de Drogas, y tercero, la normativa europea de legislación contra las drogas y delincuencia organizada.

En las legislaciones internas, destacan tres modelos normativos contra la delincuencia organizada, a) La Conspiracy Lawdel Common Law, b) La Ley R.I.C.O. -Racketeer Influenced and Corrupted Organizartion de 1970 de los Estados Unidos de América; c) el modelo de la Ley Rognono -La Torre de 1982 en Italia. Otros modelos importantes de legislaciones contra la delincuencia organizada lo representan la legislación francesa, la Ley Federal contra la Delincuencia Organizada de México de 1996 y la legislación colombiana en su artículo 186 de su Código Penal. Las leyes contra la delincuencia organizada tienen por objeto sancionar a la delincuencia de este tipo y para ello construyen tipos penales especiales y nuevos medios de prueba, así como nuevas formas de admisibilidad y de evaluación de la prueba.

En este sentido, las leyes contra la delincuencia organizada representan un nuevo paradigma jurídico- dogmático en la conceptualización de este fenómeno nocivo, a través de la construcción de nuevos tipos penales, así como de instrumentos, herramientas e instituciones penales.

En este sentido, la figura de la recompensa en materia penal ha sido incorporada recientemente en la legislación mexicana como una herramienta, y donde la participación ciudadana juega un papel preponderante, para facilitar la captura de criminales vinculados a la delincuencia organizada.

Debo resaltar que en el pasado 4 de Agosto, durante el periodo extraordinario de sesiones se presentó y modificó en el Senado una Minuta con proyecto de Decreto por el que se adiciona un segundo párrafo del artículo 37 de la ley Federal contra la delincuencia organizada. La adición tiene por objeto: Primero, que la autoridad ofrezca recompensa a quienes en los casos de secuestro, y sin haber participado en el delito, auxilien a la autoridad con información cierta y eficaz para la liberación de las víctimas o la aprehensión de los presuntos responsables, y segundo, se obliga a las autoridades salvaguardar la confidencialidad del informante.

Sin duda, el contenido del artículo 37 -así como sus adiciones en ciernes- representan un avance significativo. Sin embargo, el contenido del precepto legal resulta aún insuficiente para consolidar a las recompensas como verdaderos instrumentos útiles y efectivos para abatir el crimen.

Y efectivamente, en el combate a la delincuencia las autoridades encargadas de la justicia y la seguridad públicas deben allegarse información valiosa.

Si para lograr la aprehensión de los malhechores, o para rescatar a las víctimas de los secuestros, la autoridad necesita urgentemente de indicios o datos, entonces no deben escatimarse los esfuerzos para contar con tal información. En este sentido, resulta conveniente replantear el esquema institucional de las recompensas estableciendo las condiciones necesarias para su operación.

Hay que destacar que países como Estados Unidos e Inglaterra han institucionalizado las recompensas desde hace ya un buen tiempo. 
En Estados Unidos el sistema de recompensas ha dado buenos resultados. Basta con revisar los boletines que sobre las recompensas ofrecen a la DEA y al FBI para hacer un breve diagnóstico sobre su efectividad. Es más, tras los sucesos del 11 de septiembre de 2001 se aprobó recientemente la Ley Patriota que aumenta la cuantía de las recompensas en los casos de terrorismo. Incluso, es pertinente destacar que desde finales de 2003 el FBI y la empresa Microsoft constituyeron un fondo de cinco millones de dólares para ofrecer recompensas por los ciber piratas que introduzcan virus en Internet.

En Latinoamérica, Guatemala, Colombia y Argentina cuentan con sistemas o programas permanentes de recompensas en materia penal.

En Argentina, y desde agosto de 2003, opera la Ley 25.765. Esta Ley detalla las condiciones para fijar el monto de la recompensa, así como el lugar para su cobro; garantiza la confidencialidad del informante, no obstante, puede ser solicitado como testigo por el Tribunal de la causa si le resulta imprescindible para el juicio, y se establece además una serie de restricciones y limitantes al sistema de recompensas"1

\section{REFERENTE NACIONAL}

En Colombia, a partir de la promulgación de la Constitución Política de 1991, encontramos la Ley 418 de 1997, por la cual se consagran unos instrumentos para la búsqueda de la convivencia..., la cual en el artículo 122 al crear el Fondo Nacional de Seguridad y Convivencia Ciudadana, administrado por el Ministerio del Interior, entre otras cosas invierte recursos en: "...recompensas a personas que colaboren con la justicia y con organismos de seguridad del Estado...”.

La citada Ley 418 de 1997, fue modificada por la Ley 782 de 2002 y tiene origen en la ley 104 de 1993.

También se encuentra la ley 282 de 1996, por la cual se dictan medidas tendientes a erradicar algunos delitos entre los cuales aparece el artículo 13 sobre las recompensas, que dice:

"Las autoridades competentes podrán reconocer el pago de recompensas monetarias a la persona que, sin haber participado en el delito, suministre información eficaz que permita la identificación y ubicación de los autores o partícipes de un delito de secuestro, extorsión, o la ubicación en donde se encuentra un secuestrado o víctima de atentado contra la libertad personal.

La autoridad que reciba la información deberá constatar la veracidad, utilidad y eficacia de la misma para enviar la certificación correspondiente al funcionario competente para que se proceda al pago. El Gobierno Nacional reglamentará el contenido de la certificación y los requisitos para su otorgamiento.

1. Cf. Comentario de Antonio Santiesteban Ruiz, al proyecto de decreto por el que: "se crea la Ley Federal de Recompensas en Materia Penal y se adiciona el Artículo 49 de la Ley Federal para la administración de Bienes Asegurados, Decomisados y Abandonados" Notas en la Web. 
En ningún caso se procederá el pago de recompensas con cónyuge, compañero o compañera permanente, ni a los parientes dentro del cuarto grado de consanguinidad, segundo de afinidad o único civil del secuestrado".

Es importante resaltar entre otras, la sentencia c- 459 de la H. corte Constitucional, del 11 de Mayo de 2004, expediente No. D-4910, magistrado Ponente Dr. Jaime Araujo Rentería, quien al declarar exequibles los artículos 39, 40 de la Ley 472 de 1998, que consagra incentivos económicos a favor de los demandantes de las acciones populares, dijo lo siguiente en cuanto al tema materia de estudio:

“... es innegable la coexistencia que se dé entre el interés personal y el interés público, donde, mientras el primero se destaca por la promoción del bienestar propio, el segundo, se erige hacia la promoción del bienestar colectivo. (...)

Ahora bien, la sincronía del interés personal y del interés público depende tanto de la política de Estado como de los motivos y fines que guíen la acción de los individuos en los modelos previstos: el egoísta, el altruista y el benevolente. Siendo claro que una política que auspicie el fortalecimiento dinámico de los valores fundamentales de la comunidad se verá mejor servido con la concurrencia de múltiples voluntades benevolentes. Así las cosas, la prevalencia del interés público debe edificarse sin anular los legítimos intereses de los particulares, por lo cual, si bien estos pueden ser limitados en virtud de los públicos, tal circunstancia no puede extenderse válidamente hacia la negociación del individuo. El esquema de incentivar con estímulos económicos la colaboración de los ciudadanos con la justicia no es raro y su aplicación más relevante se encuentra en el derecho penal...

El incentivo económico es una manera de compensar la carga que asume el demandante, pues de no existir sería una carga desproporcionada para quien inicia la acción...”.

\section{EXPERTOS ANALIZAN LA POLÍTICA DE RECOMPENSAS DEL GOBIERNO}

Parte de la política de Seguridad Democrática del ex presidente Álvaro Uribe Vélez se basaba en la utilización de la figura de los informantes; que no es otra cosa que la denominación para quienes daban información al gobierno a cambio de una suma de dinero: la recompensa.

Gran parte del éxito de esta política se debe al pago de recompensas, el gobierno ha entregado más de $\$ 30.000$ millones de pesos, por ejemplo en el 2008 por la muerte de Raúl Reyes e Iván Ríos o la entrega del principal jefe militar del ELN.

En algunas ocasiones ha surtido el efecto contrario y esas delaciones han terminado en procesos jurídicos en contra del Estado, como ocurría con las organizaciones ilegales en Bogotá que contrataban personas o el caso de los policías en la costa que alertaban de posibles atentados creados por ellos mismos, para recibir beneficios y logros destacados en sus hojas de vida.

Los voceros de organizaciones sociales aseguran que la información a las agencias de seguridad del Estado es un deber de los competentes, pero es inoportuno y abiertamente inconstitucional involucrar a la población civil, además de que no están preparados para ello y se constituye en una fuente de ingreso poco usual y nada ético. 
Como el tema de las recompensas ha suscitado gran controversia y opiniones encontradas, la Revista CAMBIO consultó a seis reconocidos expertos y el siguiente es el resultado de la consulta:

\section{GUSTAVO GALLÓN, PENALISTA}

"Más allá de las recompensas, apoyarse en la población civil para realizar actividades de inteligencia es problemático porque niega el principio de distinción que afirma que los civiles deben diferenciarse de los policías y soldados, un punto básico de los D.D.H.H.

Encargar a la población de actividades ligadas a la guerra pone en peligro a la sociedad. Además una cosa es cumplir con el deber de denunciar los delitos y otra es establecer de manera permanente una red de personas para informarle al gobierno, lo cual estimula la posibilidad de que se atribuyan hechos falsos que terminen en detenciones arbitrarias como ya ha pasado. Llama mucho la atención también que el presidente haya propuesto esta red de taxistas en Cali cuando es conocido que los Rodríguez Orejuela tuvieron una red informante de taxistas. No hay que olvidar que en principio la llamada Seguridad Democrática del Gobierno hablaba de la creación de una red de informantes que involucraba a 44 millones de habitantes. Esto es una militarización de la sociedad y un estado policivo total que destruye el tejido social".

\section{JUAN MANUEL CHARRY, CONSTITUCIONALISTA}

"En el derecho francés, los sistemas de recompensa suenan bastante extraños porque se supone que colaborar con la justicia es una obligación ciudadana que no debería tener remuneración. Por eso desde este punto de vista, es difícil entender que una persona que confiesa o que colabora tenga beneficios económicos. Pero cuando pasamos al derecho anglosajón, esto ya no es extraño porque es parte del funcionamiento. Yo creo que en Colombia y en buena parte de Latinoamérica, estamos sufriendo ese tránsito de una concepción a la otra. Pero este tema de los sistemas de recompensa ya se ha introducido en el orden jurídico nuestro. Incluso creo que la Corte Suprema en los años 1989 a 1990 avaló los decretos de delación y recompensa del Estado de Sitio del gobierno Barco. Ya cuando la red de informantes es en las universidades, considero que es una medida de carácter policial que polariza la sociedad. Se supone que en un Estado típicamente liberal, el ciudadano no tiene por qué tomar partido sino que la autoridad es la que desempeña ese rol".

\section{ALFREDO RANGEL, DIRECTOR FUNDACIÓN SEGURIDAD Y DEMOCRACIA}

"Este sistema de recompensas en Colombia no es nuevo. Lo nuevo es que el gobierno del presidente Uribe ha generalizado la información de esas redes de informantes voluntarios. Desde hace más de 15 años ha habido muchas iniciativas urbanas que incorporan a los civiles, también de manera voluntaria, para entregar información a las autoridades para prevenir el delito o para capturar delincuentes, como los frentes locales de seguridad en Bogotá. El propósito de estas redes es denunciar delincuentes y delitos comunes, por lo tanto, no tendría por qué polarizar a la sociedad. Esta es una forma de promover lo que es un deber constitucional y legal de todos los ciudadanos, que es el de colaborar con las autoridades y denunciar los delitos. Si vemos el 
funcionamiento de esas redes en los últimos siete años, yo diría que son más los beneficios que los perjuicios que le ha traído a la seguridad del país y de los ciudadanos".

\section{CESAR TORRES, HISTORIADOR}

"Los sistemas de recompensas en Colombia y la actividad de informantes no son algo nuevo. Esto tiene antecedentes en la historia del país, en la Guerra de los Mil Días, en la gran violencia de finales de los años cuarenta con la persecución de los célebres bandoleros, durante el gobierno de Olaya Herrera con la actividad de las denominadas policías cívicas, bajo los gobiernos conservadores de Ospina Pérez o Laureano Gómez, en fin. Las recompensas parten de esa red de informantes al servicio del Estado, que bajo el argumento "construirpaís", adelantan acciones de tipo policíaco, militar y a su vez, de delación. Los antecedentes demuestran que la democracia y las libertades ciudadanas y políticas se fueron al traste debido a esta clase de políticas de recompensas e informantes, que ahora se nos presentan como novedosas y que nos van a afectar profundamente. Vamos a llegar a exaltar a los caza recompensas, terrible".

\section{MAURICIO PAVA, ABOGADO PENALISTA}

"Creo que desde el punto de vista jurídico, no hay manera de sostener el sistema de recompensas y la justicia "premial", si queremos tener un Estado Social de Derecho. Si bien es evidente que el sistema de recompensas político criminal ha sido un instrumento efectivo, creo que cuando se establece de forma indiscriminada la justicia pierde legitimidad. Una cosa fue la época de los carteles, en la que el Estado se sentía incapaz de dar con el paradero de Pablo Escobar o de los Ochoa, y de manera señalada y directa estableció un régimen de recompensas, y otra muy distinta, es cuando la recompensa, como sucede en este momento es de forma indiscriminada, y cualquiera puede delatar o ser delatado. Esto nos puede llevar a una situación totalitaria, como en los regímenes políticos estalinistas o los regímenes neo nacionalistas de la Alemania de la Segunda Guerra Mundial. Cuando los sistemas de recompensas son indiscriminados, se tiende a que las barreras de protección, que establecen el ordenamiento jurídico para proteger las libertades civiles, desaparezcan”.

\section{SAÚL RODRÍGUEZ, HISTORIADOR}

"En los últimos años hemos visto que en la lucha contra el narcotráfico se ha involucrado a la población civil mediante la entrega o delación de criminales a cambio de beneficios económicos. Ello ocurre por la fuerte influencia que tiene Estado Unidos, país que tiene una tradición de sistemas de recompensas que viene del siglo XIX, especialmente en las tierras de fronteras o tierras del oeste. En Colombia, sin embargo, estos sistemas han tenido efectos muy negativos que se desprenden de involucrar a la sociedad civil en temas que le competen únicamente al Estado. Estos temas de información y recompensas se han dado en momentos de convulsión estatal y social, en los que hay un aumento de la criminalidad, donde las autoridades no tienen capacidad de capturar a estos individuos indeseables".

\section{ANÁLISIS DE LA CONSULTA}

Del análisis de la consulta a los seis reconocidos expertos se coligen las siguientes consideraciones: 
Las políticas de recompensas han existido de tiempo atrás y se han aplicado en el derecho anglosajón y el derecho francés.

En la Seguridad Democrática del gobierno pasado fue donde más se dio la figura de informantes que no es otra cosa que las recompensas.

El sistema de recompensa ya se ha introducido y aplicado en nuestro sistema jurídico.

La propuesta de incluir a la población civil en la aplicación de recompensas, es un riesgo ya que el ejercicio de la seguridad pública no es esencia de los ciudadanos sino de los funcionarios encargados de la seguridad del país.

Gracias al sistema de recompensas se han logrado capturas significativas como la de Raúl Reyes, entre otras.

Si se quiere sostener un Estado Social De Derecho no hay manera de sostener jurídicamente el sistema de recompensas.

Las recompensas obedecen a la incapacidad del Estado de resolver los problemas de delincuencia y criminalidad en que se ha visto envuelto el país durante las últimas décadas.

En últimas la población civil no es la responsable ni está preparada para asumir la delicada tarea del Estado de salvaguardar la seguridad.

La mayoría de los consultados concuerda en la lesividad de esta figura.

\section{MARCO LEGAL Y JURISPRUDENCIAL}

Se revisa la LEY 1097 DE 2006 que resulta ser pertinente con la investigación, y radica en que los dineros destinados al pago de recompensas se encuentran descritos en la Ley marco de dicha figura, como gastos reservados. Así los artículos clave de esta ley son el 1 y 2 , que de un lado describen y delimitan los conceptos de gastos reservados y de otro indican las autoridades autorizadas para realizar tales gastos. Tema que tiene desarrollo en el texto amplio del proyecto y su desarrollo.

También se observó la LEY 1106 DE 2006, siendo pertinente con la investigación que se está adelantado, se encuentra en el artículo 4 que modificó el artículo 67 de la Ley 418 de 1997, prorrogada y modificada por las Leyes 548 de 1999 y 782 de 2002, que toca el tema de la protección a víctimas, testigos e intervinientes en el proceso penal. Y como quiera que dicha protección está contemplada en la ley de recompensas como un beneficio que reciben los informantes además de los económicos y reconocimientos.

Se delimita la responsabilidad de la protección a la Fiscalía General de la Nación, así como quienes pueden ser protegidos y en qué casos, indicando siempre que la protección se extenderá al grupo familiar hasta el 4 grado de consanguinidad, segundo de afinidad y primero civil, así como a los cónyuges. 
Se acompaña al trabajo de investigación el DECRETO 128 DEL 22 DE ENERO DE 2003, en que dentro del marco legislativo referido al tema de recompensas se considera la Ley 418 de 1997, prorrogada y modificada por la Ley 548 de 1999_y la Ley 782 de 2002, entregando unos instrumentos para asegurar la vigencia del Estado Social y Democrático de Derecho y garantizar la plenitud de los derechos y libertades fundamentales reconocidos en la Constitución Política y en los Tratados Internacionales aprobados por Colombia; la norma anteriormente citada dispone otros asuntos de interés que se recopilan en el trabajo matriz del desarrollo de la investigación.

Valga resaltar su artículo $4^{\circ}$ Del Programa de Protección de Testigos de la Fiscalía General de la Nación. El artículo 67 de la Ley 418 de 1997, prorrogada y modificada por las Leyes 548 de 1999 y 782 de 2002, quedará así: Créase con cargo al Estado y bajo la dirección y coordinación de la Fiscalía General de la Nación, el "Programa de Protección a Testigos, Víctimas, Intervinientes en el Proceso y Funcionarios de la Fiscalía", mediante el cual se les otorgará protección integral y asistencia social, lo mismo que a sus familiares hasta el cuarto grado de consanguinidad, segundo de afinidad, primero civil y al cónyuge, compañera o compañero permanentes, cuando se encuentren en riesgo de sufrir agresión o que sus vidas corran peligro por causa o con ocasión de la intervención en un proceso penal. En los casos en que la vida del testigo o denunciante se encuentre en peligro, la Fiscalía protegerá la identidad de los mismos. Para efectos de protección por parte del programa, se entenderá por testigo la persona que ha tenido conocimiento de la comisión de un delito, o cualquier otra circunstancia que resulte relevante para demostrar la responsabilidad penal, que en concepto del funcionario judicial competente está en disposición de expresarlo durante la actuación procesal y de ello se derive un riesgo para su vida o integridad personal. Así mismo, estarán a cargo del programa, los testigos de aquellos casos de violación a los Derechos Humanos e infracción al Derecho Internacional Humanitario, independientemente de que no se haya iniciado el correspondiente proceso penal. Ley 1106 de 2006 5/, señala en su artículo $5^{\circ}$ De las alertas tempranas. El artículo 105 de la Ley 418 de 1997, prorrogada y modificada por las Leyes 548 de 1999 y 782 de 2002, quedará así: Corresponde al Presidente de la República conservar en todo el territorio nacional el orden público y restablecerlo donde fuere turbado. Los Gobernadores y Alcaldes deberán atender de manera urgente las recomendaciones y alertas tempranas emanadas del Gobierno Nacional, especialmente del Ministerio del Interior y de Justicia, tendientes a prevenir, atender y conjurar las situaciones de riesgo que alteren el orden público, y las posibles violaciones a los derechos humanos o el Derecho Internacional Humanitario.

\section{DECRETO 395 DE 2007}

Interesa ver el DECRETO 395 DE 2007 emitido el 14 de febrero que tiene por propósito reglamentar la Ley 418 de 1997 prorrogada y modificada por las Leyes 548 de 1999, 782 de 2002 y 1106 de 2006 y se modifica parcialmente el Decreto 128 de 2003.

Ello en consideración que la Ley 418 de 1997, prorrogada y modificada por las Leyes 548 de 1999, 782 de 2002 y 1106 de 2006, "consagró unos instrumentos para asegurar la vigencia del Estado Social y Democrático y de Derecho y garantizar la plenitud de los derechos y libertades fundamentales reconocidos en la Constitución Política y en los Tratados Internacionales aprobados por Colombia".

\section{DECRETO 2271 DE 1991}


La importancia y pertinencia de este decreto radica en que en su artículo 1 ratifica y manifiesta que será legislación permanente el Decreto Legislativo 1199 de 1987, en su artículo 1 que reza:

"Quien suministre a la autoridad informes que permitan hacer efectivo el cumplimiento de órdenes de captura dictadas con ocasión de la comisión de delitos en el territorio nacional o fuera de él, podrá ser beneficiario de una recompensa monetaria.

Esta misma recompensa podrá ser reconocida a la persona que suministre informaciones y pruebas eficaces que fundamenten la responsabilidad penal o permitan hacerla extensiva a otras personas",

Entonces, con el contenido de este decreto se ratifica el uso de las recompensas como mecanismo en contra de los grupos armados, legitimando de ese modo el uso de incentivos para lograr resultados a través de delaciones y no por operaciones de inteligencia militar.

De otro lado relaciona aspectos importantes sobre la reglamentación del uso de las recompensas, tanto para particulares como para militares que logren resultados a través del uso de información obtenida, y que luego será remunerada con beneficios económicos o de promoción al interior de la institución, lo cual desnaturaliza el hecho mismo de la labor ciudadana en la colaboración, toda vez que determina que quien suministre información lo haga por el dinero que se puede llegar a recibir, y no por el deber legal que le asiste de denunciar hechos delictivos o personas involucradas en ellos.

\section{DECRETO LEGISLATIVO 2110 DE 1992}

Dicho decreto se relaciona con el contenido de la investigación, pues marca pautas y parámetros sobre temas de seguridad nacional, en que se encuentran las recompensas, y así mismo reglamenta al DAS. Es importante aclarar que sobre este decreto existen son resúmenes y no se encontró un documento que contenga el texto completo del mismo.

Sigue dentro del trabajo de investigación referencia a cierta operatividad frente a las recompensas y su regulación jurídica, atinentes a directivas permanentes y de otro orden que invita a leer en extensión el documento que desarrolla en completud lo pretendido en el trabajo académico. Siendo del caso decir, que el grupo para el Programa de Atención Humanitaria al Desmovilizado, respecto a los criterios de valoración en cuanto a la bonificación por entrega de armas, establece una tabla que consigna en el documento de la directiva del Ministerio de Defensa Nacional identificado con el número 16 del año 2007, expresada en pesos colombianos que oscila entre $\$ 3.000 .000,00$ y $\$ 100,00$; material de intendencia entre $\$ 200.000,00$ y $20.000,00$; equipo especial entre $\$ 18.000 .000,00$ y $\$ 500.000,00$; material de comunicaciones entre $\$ 3.000 .000,00$ y $\$ 200,00$, armas no convencionales y explosivos entre $\$ 200.000,00$ y $\$ 500.000$; sistemas entre $\$ 1.500 .000,00$ y $\$ 20.000,00$, vehículos $\$ 20.000 .000,00$ y $\$ 30.000,00$; narcotráfico e insumos químicos entre $\$ 500.000,00$ y $\$ 180,00$, Maquinaria industrial $\$ 10.000 .000,00$ y $\$ 300.000,00$ y así sucesivamente otros ítems.

Es de señalar respecto al tema de Denuncia y Declaración que se predica y otros aspectos de interés, se señala literalmente:

"El pago debido por denunciar miembros de las organizaciones armadas al margen de la ley se llevará a cabo cuando la denuncia conduzca a la vinculación mediante indagatoria o 
declaratoria de persona ausente, orden de captura, la detención preventiva con o sin beneficio de excarcelación, resolución de acusación o sentencia condenatoria de cualquiera de las personas denunciadas o de todas ellas, de conformidad con la Ley 600 de 2000.

El pago debido por denunciar miembros de las organizaciones armadas al margen de la ley se llevará a cabo cuando la denuncia conduzca a la formulación de imputación, medida de aseguramiento, orden de captura, acusación o sentencia condenatoria de conformidad con la Ley 906 de 2004.

El pago debido por declarar en contra de los miembros de las organizaciones armadas al margen de la ley se llevará a cabo cuando la declaración o el testimonio prestado durante cualquiera de las etapas del proceso penal conduzca a la vinculación mediante indagatoria o declaratoria de persona ausente, la detención preventiva con o sin beneficio de excarcelación, la resolución de acusación o la sentencia condenatoria contra cualquiera de las personas contra las que se declara de conformidad con la Ley 600 de 2000 o formulación de imputación, medida de aseguramiento, orden de captura, acusación o sentencia condenatoria de conformidad con la Ley 906 de 2004.

Para proceder al pago respectivo por denuncia o declaración, se requerirá una certificación de la autoridad judicial correspondiente (Fiscal Delegado o Juez de la República), en la que conste la información básica del proceso (radicación, estado procesal, indiciado, denunciado o investigado con la posición que ocupaba en la organización) de cualquiera de las situaciones arriba enumeradas o las situaciones equivalentes contempladas en el régimen penal o procesal penal vigente.

La bonificación no es acumulativa y sólo se pagará cuando se presente cualquiera de las situaciones arriba enumeradas según se trate de denuncia o declaración en cualquiera de sus etapas. Allí se tienen acápites contemplativos en cuantos bienes Inmuebles, estupefacientes e Insumos Químicos, resultados No Tangibles, bonificaciones y Límites, recursos entre otros puntos que se trabajaron en su momento en el documento fuente del presente artículo"

\section{ALGUNAS APRECIACIONES DE CARÁCTER JURISPRUDENCIAL}

\section{SENTENCIA C-683/96}

Magistrado Ponente: Dr. Fabio Morón Díaz

Cuya pertinencia se encuentra relacionada con el tema objeto de estudio, ya que las normas declaradas exequibles tocan temas como las recompensas. En tal sentido se indica por la corte que es absolutamente legítimo por parte del Estado ofrecer dinero a quienes brinden información oportuna y eficaz, para capturar personas que hayan cometido ilícitos, así como bienes producto de aquellos. Reclama el demandante que con dicho comportamiento se están motivando fines mercantilistas y no altruistas al momento de elevar una denuncia o brindar información, pues quien lo hace tiene como fin recibir un dinero y no el cumplimiento de un deber legal; por lo que la corte manifiesta que si bien existe esa posibilidad, es deber del Estado garantizar la seguridad de sus asociados, y si para lograr ese cometido debe valerse de información remunerada bien puede hacer, siempre y cuando no se vulneren principios fundamentales. 
Se destaca el poder del Estado para determinar las normas que a bien tenga para lograr sus funciones principales, y por tanto puede a través del sistema de recompensas combatir a los criminales.

Para iniciar es preciso advertir el establecimiento legal del incentivo material que utiliza el Estado como forma de estímulo para varios propósitos, entre ellos, el dispuesto en la Ley 472 de 1998, declarando la Corte Constitucional exequible el artículo 40 ídem (C-459/04) que establece el incentivo a favor de quien demanda en acción popular, bajo el argumento:

"El esquema de incentivar con estímulos económicos la colaboración de los ciudadanos con la justicia no es rara y su aplicación más relevante se encuentra en el derecho penal.

El incentivo económico es una manera de compensar la carga que asume el demandante, pues de no existir sería una carga desproporcionada para quien inicia la acción...".".

Continuando con el tema jurisprudencial respecto de la recompensa, la misma Corte Constitucional, en la T-139 de 1993, analizando el principio de fraternidad originado en la Revolución Francesa de 1789, consideró que:

“... es un hecho real que existe la solidaridad entre los hombres para el bien y para el mal. Hay un ejemplo que se suele citar con mucha frecuencia: el de las enfermedades contagiosas. Uno tiene que preocuparse porque las gentes se vacunen y por cuidar a los enfermos, no solamente para que ellos se salven, sino también para evitar que su enfermedad se trasmita a otros. Y de esa solidaridad nadie puede escapar. La proliferación de tugurios en las grandes urbes es otro ejemplo. Ella daña la estética y la bigiene de las ciudades; crean nuevas formas de delincuencia; hace peligrosa e incómoda la vida de las clases más acomodadas. En lo internacional se ha dicho que la paz, como la prosperidad son indivisibles. Lo mismo ocurre en lo interno, somos solidarios, nadie vive aislado en el seno de la sociedad sino que es una parte de ella, y la conclusión lógica de esa innegable solidaridad en el seno de cada nación y también en el ámbito internacional es revivir o afianzar lo que se llamó (fraternidad). Si somos solidarios tenemos que acudir al remedio de las desigualdades y de los males de los demás con espiritu al que se mezclan ciertamente sentimientos utilitaristas, porque queremos defendernos contra los peligros que la situación de los otros puede provocar...".

Ya con el decreto 2110 de 1992, donde se faculta a director del DAS a reconocer recompensas en aras de materializar capturas por la comisión de delitos, dijo la Corte Constitucional en la T-561 de 1993:

"...las autoridades de la República obran conforme a derecho en cumplimiento de una norma que hace parte de nuestro ordenamiento jurídico, al ofrecer públicamente recompensas por informaciones que faciliten la captura de cualquier clase de delincuentes..."'.

En esa misma orientación y en aval de la recompensa como forma legal y legítima de combatir el delito, la Sala de Casación Penal de la Corte Suprema de Justicia, al resolver en sede de segunda instancia un proceso penal por prevaricato contra un juez de la república, quien precisamente amparó derechos fundamentales de quien en su momento fue objeto del sistema de publicación para recompensa por su captura, sostuvo:

2. C-459 de 2004. Corte Constitucional.

3. T-139/93 Corte Constitucional.

4. T-561/93 Corte Constitucional. 
... las campañas publicitarias por recompensas para el cumplimiento de la ley son apenas, actos de legítima defensa del orden social, que el Estado está obligado a ejecutar".".

En contraposición a quienes estiman que la recompensa aleja al ciudadano del deber de cumplir el deber de denunciar y colaborar, la misma Corte Constitucional en la T-561 de 1993, motivó:

“... las organizaciones criminales son poderosas, y combatirlas en una u otra forma implica riesgos para el ciudadano inerme. La recompensa, entonces, implica una compensación por los riesgos que la persona asume al denunciar al criminal que bace parte de una organización..."

Precisamente, para seguir resolviendo el interrogante del enfrentamiento entre el deber de denunciar y el incentivo por hacerlo en la misma sentencia T-561 de la Corte Constitucional, insistió en que:

"...es verdad que entre los deberes de la persona y el ciudadano, según el artículo 95 están los de "respetar y apoyar a las autoridades democráticas legitimamente constituidas", propender al logro y mantenimiento de la paz", y "colaborar al buen funcionamiento de la administración de justicia"; y que esto podría llevar a la conclusión errónea de que la colaboración para la captura de los delincuentes tiene que ser forzosamente desinteresada, no remunerada" 7 .

Ante el viejo apotegma de que debe prevalecer el interés general sobre el interés particular, es la misma Corte Constitucional en la jurisprudencia que se viene tratando, esto es, la T-561 de 1993, y bajo el entendido de que las autoridades están instituidas para proteger a todas las personas residentes en Colombia en su vida, honra y bienes y demás derechos y libertades, estimó que:

"...la existencia misma del Estado se justifica precisamente en cuanto éste es un mecanismo para proteger a las personas en sus derechos fundamentales, en especial la vida y la libertad. Esta protección se cumple en dos fases: una preventiva destinada a impedir la acción de los delincuentes; y otra posterior a la comisión de los delitos; cuyo fin es castigarlos e impedir que se repitan... la tarea más urgente que tiene el Estado en Colombia es la eliminación de las ORGANIZACIONES CRIMINALES, pues mientras ellas existan seguirán cometiendo los desmanes que son la manifestación de su conducta habitual. Dicho en otros términos: el orden jurídico es incompatible con la existencia de organizaciones criminales dedicadas a su desconocimiento".

Pese a todo lo anterior, al interior de la misma Corte Constitucional existió oposición a tal forma de avalar el incentivo como recompensa, como el salvamento de voto del Magistrado Jorge Arango Mejía, quien estimó que:

“... el Estado no puede patrocinar campañas publicitarias que desconozcan los derechos, principios y valores que precisamente lo distinguen de las organizaciones criminales que combate. La legitimidad del Estado no solo proviene de su capacidad para capturar a los presuntos delincuentes, sino también de su capacidad para juzgarlos y condenarlos dentro de los cauces del procedimiento legal y con respeto de todas las garantías juridico -penales.

5. Corte Suprema de Justicia.

6. $T-561 / 93$ Corte Constitucional.

7. T-561/93 Corte Constitucional.

8. $T-561 / 93$ Corte Constitucional. 
Solo con esta combinación de fuerza y derecho, el monopolio de la violencia en cabeza del Estado aparece como algo necesario y, además como algo legítimo"."

\section{CONCLUSIONES}

El ofrecimiento y pago de recompensas económicas ha sido durante siglos una práctica común al desarrollo de muchas políticas públicas estatales en el mundo.

La recompensa ha sido utilizada desde siglos pasados en diversos países con resultados favorables para el logro de fines positivos. acerca de delitos de lesa humanidad y en general conductas lesivas a los D.D.H.H.

En un Estado social de derecho no debería existir la figura de la recompensa, pero dado el alto índice de violencia en algunos países denominados democráticos, los gobernantes han recurrido a ella a fin de aliviar el flagelo que traen consigo la guerrilla, los paramilitares, las bandas criminales (BACRIM), entre otras formas de grupos al margen de la ley.

Debe prevalecer el interés general sobre el interés particular en definición de situaciones que tengan que ver con la aplicación de la ley de recompensas.

La ley de recompensas no puede quebrantar los derechos humanos y las normas de Derecho Internacional Humanitario.

Las recompensas deben responder a una cooperación transparente y eficaz.

Se deben seguir los lineamientos de los fallos de la Corte Penal Internacional y de las instituciones de regulación de la justicia de Derechos Humanos y Derecho Internacional Humanitario, que permitan crear una línea jurisprudencial para la resolución de los casos.

La ley de recompensas no puede ser un espacio para fomentar los falsos positivos.

Teniendo en cuenta que la recompensa se define como una remuneración, podemos concluir que ésta se da teniendo en cuenta si es por colaboración, por servicios o simplemente por información, por ello el incentivo varía de acuerdo a la retribución o la seguridad y efectividad de la información o servicio recibido.

\section{BIBLIOGRAFÍA}

- DE CASTRO CID, Benito: "Introducción al estudio de los Derechos Humanos", Editorial Universitas, Primera edición 2003.

- MARTÍNEZ DE AGUIRRE, Carlos: "Promesa pública de recompensas", editorial Temis, 1984.

- GUZMÁN DALBORA, José Luis: “Cultura y delito”, editorial Temis, 2010.

9. Salvamento de Voto Magistrado Jorge Arango Mejía. 
- SILVA SÁNCHEZ, Jesús María: “Aproximación al derecho penal contemporáneo”, editorial B de F, 2010.

- KAI AMBOS "Imputación de crímenes de los subordinados al dirigente", editorial Temis, 2008.

- ----------"Procedimiento de la Ley de Justicia y paz (ley 975 de 2005) y Derecho penal Internacional”, editorial Temis, 2010.

- NEIRA FERNÁNDEZ, ENRIQUE, “¿Qué paz quieren las guerrillas?”, Observatorio de Política Internacional. Consulta realizada en agosto de 2008.

NORMATIVA

- CONSTITUCIÓN POLÍTICA DE COLOMBIA, editorial Leyer, año 2001.

- CÓDIGO PENAL COLOMBIANO: editorial Leyer. Año 2011.

- LEY 418 DE 1997.

- LEY 548 DE 1999.

- LEY 1097 DE 2006.

- LEY 1106 DE 2006.

- DECRETO NÚMERO 2767 DE 2004 Ministerio de Defensa.

- DECRETO 395 DE 2007.

- DECRETO 1664 DE 2007.

- DECRETO 2271 de 1991.

- DECRETO 128 DE 2003.

- DECRETO 1199 DE 1987.

- DIRECTIVA MINISTERIAL PERMANENTE No. 15 / 2007 Ministerio de Defensa.

- DIRECTIVA MINISTERIAL PERMANENTE No. 16 / 2007 Ministerio de Defensa.

- DIRECTIVA MINISTERIAL PERMANENTE No. 300 / 2007 Ministerio de Defensa.

\section{JURISPRUDENCIA}

- Sentencia T-139 de 1993 Corte Constitucional.

- Sentencia T-561 de 1993 Corte Constitucional.

- Sentencia C-459 de 2004, H Corte Constitucional.

- Sentencia No. T-611/92.

- Sentencia No. T-561/93.

\section{DOCTRINA}

- EL TIEMPO. "Cronología del proceso a los jefes paramilitares desde su desmovilización”.

- "Expertos analizan la política de recompensas del Gobierno", Revista Cambio, 19 de junio de 2012, www.cambio.com.co

- GALVIS MARTINEZ, MANUEL: "El uso de recompensas en el conflicto armado colombiano" pp 209-242, ACDI, 2010. 